\title{
Health mutual fund: Reality or a myth?
}

Background: In the pluralistic environment of Indian healthcare financing system, community based health insurance $(\mathrm{CBHI})$ holds promise to reduce the share of out of pocket (OOP) expenditure on healthcare by the households. The present study explores the extent to which the mutual model of $\mathrm{CBHI}$ could reach the socially and economically marginalized population along with investigating the reasons of drop-outs from the scheme in the city of Mumbai and Pune. Methods: This study used a cross sectional exploratory study method, using simple random method, conducted in slums of Mumbai and Pune. Results: The financial protection provided through health mutual fund (HMF) is still on the lower side when compared with annual OOP expenditure due to health by the household. The enrolment pattern shows that the scheme covers the marginalized people belonging to lower castes and minority community, employed in the unorganized sector. HMF is playing an important role in providing financial protection against the high frequency illness which is not covered under state sponsored schemes. Conclusion: Factors behind the members dropping out of the scheme were found to be no benefit from the scheme, inability to pay a premium, member of Employees State Insurance Scheme, unsatisfactory services from network provider and past negative experiences including claim rejection or low reimbursement. The study holds larger policy implications as there is limited study conducted to know the pattern of enrolment and exploring reasons of low rates of renewals.

Key words: Community-based health insurances, health mutual fund, "mutual" model of community-based health insurance, out of pocket expenditure

Richa Salvi, Nayan Chakravarty ${ }^{1}$

Technical Program Officer, SETU Core+, Family Planning Association of India, Bajaj Bhavan, Nariman Point, Mumbai, ${ }^{1} I \mathrm{IPH}$ Bhubaneswar, Public Health

Foundation of India, Patia,

Bhubaneswar, Odisha, India

Address for the Correspondence:

Mr. Nayan Chakravarty, Public Health Foundation of India, JSS Software Technology Park, E 1/1, 3rd floor, Infocity Road, Patia, Bhubaneswar-751024, Odisha, India.

E-mail: nayan0705@gmail.com

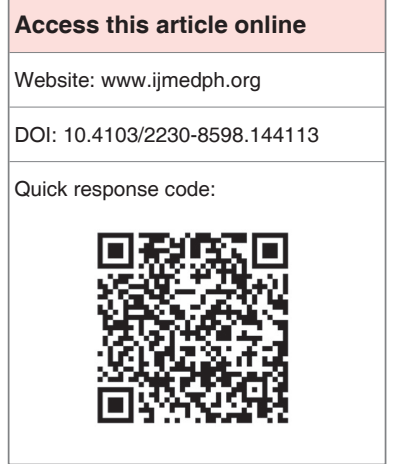

\section{INTRODUCTION}

\section{Background of the study}

Indian health care system relies heavily on out of pocket (OOP) expenditure for financing health care. According to national health accounts, India report (2009) households contributed a significant portion at $71.13 \%$ (2004-2005) of total health expenditure for availing health care services from different health care institutions. ${ }^{[1]}$ This includes expenditure on in-patient, out-patient care, family planning, immunization, etc. The reliance on OOP payments for financing healthcare puts the financial burden on the low-income households. Poor people either forego treatment or risk impoverishment due to unaffordable health care. A large proportion of people, especially those in the bottom four-income quintiles borrows money or sells assets to pay for hospitalization (World Bank, 2002). ${ }^{[2]}$ According to (Ghosh, 2011), ${ }^{[3]} 47$ million people (4.4\% of total population) in India were impoverished due to OOP expenditure in 2004-2005. ${ }^{[2]}$ The impoverishment due to OOP expenditure creates a vicious cycle of ill health and poverty.

In the wake of declining gross domestic product and rising health care costs, health insurance is being increasingly looked into as a way to protect people financially against the risk of illness. However, the penetration of health insurance is still low in India, and it covers around $25 \%$ of the population. ${ }^{[4]}$ The Government of India's (GOIs) social insurance schemes (Central Government Health Scheme and Employee State Insurance Scheme) mainly cater to the health needs of formal sector employees which is a very small segment. In India, about $90 \%$ of the population is employed in informal-sector. In addition, a small proportion (only $5 \%$ ) of the population is enrolled under various private health insurance plans ${ }^{[4]}$ which proves to be unaffordable to most of the low and medium income population.

Government-Sponsored Health Insurance Schemes have emerged to provide the poor with financial protection against catastrophic health shocks, defined in terms d an in-patient stay. Between 2007 and 
2010, six major schemes have emerged, including one sponsored by the GOI and five state-sponsored schemes. The target group under the Rashtriya Swasthya Bima Yojana (RSBY) scheme is below the poverty line (BPL) population. The RSBY scheme so far covers about $50 \%$ of the targeted BPL population (www.rsby.gov.in). It also neglects large section of the population which is just above poverty line (APL) and focuses only on secondary care ignoring the OOP expenditure incurred to avail the ambulatory care. The state funded health insurance schemes provide financial protection to BPL and APL families for higher cost tertiary care. The beneficiaries under these schemes are still left with no financial protection against healthcare expenditure incurred due to ambulatory care. The existence of community-based health insurance ( $\mathrm{CBHI}$ ) schemes is to bridge the gap between the governments sponsored and privately owned and managed health insurance schemes.

\section{Community-based health insurance}

Community-based health insurance is referred to all nonprofit insurance scheme aimed primarily at the informal-sector and formed on the basis of a collective pooling of health risks, and in which the members participate in its own management. ${ }^{[5]}$ This definition includes Mutual Health Organizations (MHOs), local health insurances and micro health insurances. ${ }^{[6]}$ Since the 1950's CBHI is not a new phenomenon in India. Since the 1950s, nongovernmental organizations (NGO) have executed local risk-pooling mechanisms to improve the access to quality care and to protect households from high health expenses. Notably in late 1990's, micro-finance movement, which encompasses micro-credit, micro-savings and micro-insurance led to spurt of CBHI schemes. At the moment, about $115 \mathrm{CBHI}$ schemes exist. ${ }^{[7]}$ There are three types of CBHIs in the country. The first type is the "direct" model, where a hospital has initiated a health insurance product. The hospital is both a provider of care as well as the insurer. The second type is the "mutual" model, where the NGO organizes and implements the insurance scheme and purchases care from various providers. The most common type is the "linked" model, where the NGO collects premium from the community and purchases insurance from a formal insurance company and healthcare from providers. ${ }^{[8]}$

The $11^{\text {th }} 5$ years plan (2007-2012) refers to CBHI as tools to extend social health protection to workers belonging to the informalsector. ${ }^{[9]}$ In the National Rural Health Mission document, CBHI has been promoted as one of the measures to bring "accessible, affordable, accountable and good quality health care." ${ }^{[10]}$ The main strengths of community financing schemes are the degree of outreach penetration achieved through community participation, their contribution to financial protection against the cost of illness, and an increase in access to health care they afford low-income rural and informal-sector workers. ${ }^{[1]}$ However, there are limitations to this scheme due to the small amounts of revenue that can be mobilized from poor communities, the frequent exclusion of the very poorest from participation unless subsidized in some way, the small size of the risk-pool, the limited existing management capacity in rural and low-income contexts, and isolation from the more comprehensive benefits often available through more formal health financing mechanisms and provider networks. ${ }^{[1]}$ Finally, many of the schemes see health insurance as an end in itself. However, it must be remembered that health insurance is a means for a more equitable and functional health system. ${ }^{[8]}$

\section{"Mutual" model of community-based health insurance}

The "mutual" model works as a CBHI which is defined as any not-for-profit insurance scheme that is aimed primarily at the informal-sector and formed on the basis of a collective pooling of health risks. ${ }^{[8]}$ In addition to this definition, Atim in his definition of "health mutuelles" stated that it is a voluntary scheme formed on the basis of an ethic of mutual aid, solidarity in which the members participate effectively in its management and its functioning. ${ }^{[12]}$ The model is based on the original historical idea of insurance, which was initially provided by mutual liability institutions to a limited member base.

In this model, an NGO provides health micro-insurance to its members directly and the risk is not necessarily passed on to an insurance company. These are referred to as in-house insurance providers. MHO are typically owned, designed, and managed by the community that they serve. Communities organize themselves to establish a health insurance system. In the process of participatory bottom-up planning, priorities are defined and important decisions, such as determining the benefit package, are taken by the communities. The beneficiaries own and manage the system themselves and therefore are the financial risk bearers. A contract is signed between each individual and all the others. They collect the premiums to cover the types of care previously defined and provided by facilities contracted. The insurer and the care provider negotiate the terms of care. Well-functioning schemes may play a strong role in defending the interests of households they represent. They can negotiate for better quality, such as better availability of essential drugs, or improved provider behavior. Members pay a small premium, on a regular basis, to offset the risk of having to pay for high health care costs in the case of illness, injury, childbirth, or any other event requiring expensive medical services. Typically, MHOs develop around a geographical entity (such as a district or a village), trade or professional group (such as a trade union or agricultural cooperative), or health care facility (provider-initiated schemes). They have democratic accountability to their members with a mission to improve their members' access to good quality health care through any of a range of financing mechanisms including insurance, simple prepayments, savings and credit and subscriptions.

\section{Health mutual fund}

Health mutual fund (HMF) is based on the mutual concept in which risks are not transferred to an insurer but shared under the community's responsibility. The family is considered basic unit and the health insurance is provided on floater basis. One policy covers all members of the family and the sum assured is available to any 
member or to all members in case of any eventuality during the term of the policy. This mechanism spreads risk equally among young and old, sick and healthy members of the family. It provides maximum coverage of 15,000 for the premium of Rs. 120/family member. The term of the insurance is 1 -year. There is active participation of community representatives accordance with the guidelines laid in the fund. The community representatives are not only the signatories of the physical fund, but they also validate all policy decisions and vote on accounts, and they take the final decision on claims paid. Thus, claims are settled in democratic and transparent way by communities themselves. Health promotion is done, and preventive guidance is given by conducting health camps, arranging health talks. HMF was first introduced in 2003 by micro-credit organization Annapurna Pariwar operating in Pune and Mumbai. The organization started its own division with an objective to provide social protection to its members through micro-insurance. There are quite a few studies investigating varies aspects of HMF. The study conducted by Leist and Radermacher ${ }^{[13]}$ offered a brief description of the Swasthyapurna HMF in Pune city. The strengths and weaknesses of the scheme have been highlighted followed by some recommendations for future improvements.

Dror et al. ${ }^{[14]}$ studied three schemes in India to examine whether micro-insurance can provide financial protection for poor households and improve access to health care. The study concludes that micro-insurance (low cost health insurance) based on a community, cooperative or mutual and self-help arrangements can provide financial protection for poor households and improve access to health care. This study pointed out that low benefit caps perversely limited these schemes' ability to extend coverage, offer financial protection and retain members. There are studies available which reflected that HMF provides access to better quality of care to its member compare to nonmember ${ }^{[15]}$ and plays an important role in reducing in reducing OOP cost for insured compare to uninsured (McGuinness 2011). ${ }^{[16]}$

However, majority of the literature available deals with the aspects of HMF such as access to quality healthcare, financial value provided to its members, transformative effect on members and extent of financial protection provided through HMF, without exploring into the pattern of enrollment into the scheme, causes behind low renewal rate of the scheme. This paper tries to explore whether scheme is including socially and economically marginalized population under its coverage. The study analyses the level of OOP expenditure incurred by examining the pattern of health care utilization by the members and financial protection provided the scheme to these members.

\section{METHODOLOGY}

\section{Study design}

The study was conducted using quantitative methodology to achieve the objectives of the study. This study is cross sectional exploratory in nature where the data has been collected from the city of Mumbai and Pune.

\section{Study setting}

The study was conducted in the slums of Mumbai and Pune city. Mumbai is the most populated city in India with more than half of its population residing in slums, and Pune is the eighth largest city in India with a population of 3.1 million (Pune Municipal Corporation 2011). There are total 564 slum pockets in the city out of which 353 are declared slums. The healthcare infrastructure in these urban regions consist of urban health centers for primary health care, municipal hospitals providing secondary and tertiary health care. However, the public healthcare is overburdened as many other cities in India.

\section{Study universe}

All members of the households those who have been presently either covered under the HMF introduced by a micro-finance organization or those past (drop-outs) members, who has dropped out in last 1 -year, forms the universe for this study. Subjects, including both insured and un-insured (one who has dropped out in the last 1-year) were selected from slums across both the city.

\section{Unit of analysis}

Household was considered as a unit of analysis as the enrollment into HMF is family based. The policyholder was considered as a respondent. Out of all insured households only those households in which at least one of the family members was hospitalized in past 1-year were included in the study. Out of past members of the schemes, the members who have dropped out during past 1-year were selected.

\section{Sampling procedure}

The branch offices of micro-finance organization working in the city of Mumbai and Pune, there working sites were considered as clusters. Once the clusters were selected, simple random sampling technique were used to select households from the list of households where at least one hospitalization event has occurred in past 1-year. Similar sampling techniques were used for both cities.

\section{Sampling procedure for un-insured}

To track the drop-out members from the scheme, similar sampling techniques were used to select un-insured households for both the city of Mumbai and Pune. The list of such un-insured (dropped out in last 1-year) was obtained from seven branch offices of the selected organization. From the list obtained, subjects were selected using a simple random technique.

All together 95 sample households were selected (for both insured and un-insured) across seven slums of Mumbai, of which 92 interviews were conducted, with three cases as unavailable. In the city of Pune, 80 households were selected including both presently insured and un-insured cases (drop-outs in last 1-year). Of the 
selected 80 cases, 74 interviews could be conducted with six cases as unavailable.

\section{Data collection tool and process of data collection}

Data collection was done in the city of Mumbai and Pune during the month of May 2012. Face to face interviews were conducted with the current and past members of the scheme. The households of the members were marked with the help of health service executives of both organizations, without prior intimation.

A structured interview schedule was prepared for both past and the current member of the HMF, which was a pilot tested first and then was administered for data collection. It has five sections on characteristics of the policyholder, characteristics of household enquiring about detailed information about the other family members, economic status of the household healthcare utilization pattern of the household, healthcare related expenditure incurred by the household and the coping strategies, and the last section was exclusively for the members who have dropped out of the scheme.

\section{Data analysis}

The data collected with the help of a structured questionnaire was analyzed by using Statistical Package for Social Sciences (SPSS) software 20 version (IBM Corp. Released 2011. IBM SPSS Statistics for Windows, Version 20.0., Armonk, NY). The data collected was transformed in to appropriate codes and then entered in the software. The coded data was analyzed using appropriate statistical tests.

\section{Confidentiality}

An informed written consent from the respondent for interviewing and utilizing the data provided was taken before conducting the interviews.

\section{Limitations of the study}

The study assumes the total amount of OOP expenditure due to out-patient care in 1 -year by multiplying OOP in 1-month by 12 . This method does not capture the OOP accurately as there can be variations in OOP throughout a year. Hence, the study provides only the estimates of per annum OOP due to out-patient care by insured households.

\section{RESULTS}

\section{Sample characteristics}

Tables 1 and 2 depicts clusterwise distribution of insured and uninsured households in city of Mumbai and Pune respectively. A total of 166 households were surveyed for the purpose of data collection in the slums of Mumbai and Pune city. These 166 households consisted total of 693 members. These members were those that were currently residing in the household and enrolled as the beneficiary of HMF. The members of the household who have migrated, and the members who were not enrolled under the HMF were excluded in the survey. The sociodemographic characteristics of this sample demonstrate the pattern of enrollment in the HMF.
The sample population predominantly composed of productive age group $(72 \%)$ with median age of 25 . The sample had more number of males $(51 \%)$ compared to females $(49 \%)$. The sex ratio for the sample was calculated to be 930 females/1000 males. Nearly half of the population was married. About $60 \%$ of households had nuclear family structure. The population predominantly (63\%) belonged to backward classes and minority community $(22 \%)$. The majority of people $(89 \%)$ were involved in low skill jobs not requiring any kind of higher education. The reasons for opting out for higher education varied from to support family by gaining employment, inability to afford further education and inability to cope up with higher education. People engaged in the unorganized sector, which did not offer any kind of social security to them. The mean income of the household was found to be about Rs. 10,000/month.

\section{Enrolment pattern in health mutual fund}

Majority of the policyholders (44\%) belong to the age group 31-40 years followed by 35\% policyholders in age group of 41-50 years. Notably, the enrollment of policyholders into HMF declines sharply in the age group above 50 years. The sex ratio of the policyholders is heavily tilted towards females with $88 \%$ of them being the policyholders. It is seen that $90 \%$ of policyholders are currently married, and only $10 \%$ are widowed or divorced.

Table 3 shows the socioeconomic profile of the policyholders in HMF. Nearly one-half of the policyholders were educated up to the secondary standard. Eight percent of people pursued education above secondary level. More than half of the policyholders $(58 \%)$

\begin{tabular}{lccc} 
Table 1: Cluster wise distribution of insured \\
and uninsured households in Mumbai \\
\hline Clusters & $\begin{array}{c}\text { Number of } \\
\text { households }\end{array}$ & $\begin{array}{c}\text { Number of insured } \\
\text { households }\end{array}$ & $\begin{array}{c}\text { Number of un- } \\
\text { insured households }\end{array}$ \\
\hline Chembur & 14 & 7 & 7 \\
Mankhurd & 15 & 7 & 8 \\
Ghatkopar & 12 & 6 & 6 \\
Kurla & 13 & 7 & 6 \\
Bhandup & 11 & 6 & 5 \\
Kalva & 12 & 6 & 6 \\
Thane & 15 & 8 & 7 \\
Total & 92 & 47 & 45 \\
\hline
\end{tabular}

Table 2: Cluster wise distribution of insured and uninsured households in Pune

\begin{tabular}{lccc}
\hline Clusters & $\begin{array}{c}\text { Number of } \\
\text { households }\end{array}$ & $\begin{array}{c}\text { Number } \\
\text { of insured } \\
\text { households }\end{array}$ & $\begin{array}{c}\text { Number of } \\
\text { un-insured } \\
\text { households }\end{array}$ \\
\hline Upper Indira Nagar & 8 & 5 & 3 \\
Lower Indira Nagar & 12 & 7 & 5 \\
Dandekar bridge & 11 & 6 & 5 \\
Kashewadi & 12 & 9 & 3 \\
Bhavani Peth & 11 & 5 & 6 \\
Annabhau Sathe Nagar & 11 & 8 & 3 \\
Ram tekdi & 9 & 5 & 4 \\
Total & 74 & 45 & 29 \\
\hline
\end{tabular}


belong to Hindu religion, followed by Muslims (30\%). More than one-half of the policyholders $(52 \%)$ belonged to backward social groups such as SC, ST and OBC. About one-fourth of the

\begin{tabular}{|c|c|c|}
\hline Socioeconomic profile & Frequency & Percentage \\
\hline \multicolumn{3}{|l|}{ Education } \\
\hline No education & 28 & 30.4 \\
\hline Up to primary & 14 & 15.2 \\
\hline Up to secondary & 43 & 46.7 \\
\hline Above secondary & 7 & 7.6 \\
\hline \multicolumn{3}{|l|}{ Religion } \\
\hline Hindu & 53 & 57.6 \\
\hline Muslim & 28 & 30.4 \\
\hline Buddhist & 11 & 12 \\
\hline \multicolumn{3}{|l|}{ Caste } \\
\hline SC and ST & 43 & 46.8 \\
\hline OBC & 5 & 5.4 \\
\hline Others & 44 & 47.8 \\
\hline \multicolumn{3}{|l|}{ Occupation } \\
\hline Unemployed & 20 & 21.7 \\
\hline Self-employed & 39 & 42.3 \\
\hline Salaried worker (unorganized) & 27 & 29.3 \\
\hline Salaried worker (organized) & 6 & 6.5 \\
\hline
\end{tabular}

$\mathrm{HMF}=$ Health mutual fund

\begin{tabular}{|c|c|c|c|c|}
\hline \multirow{2}{*}{$\begin{array}{l}\text { Number of } \\
\text { visits }\end{array}$} & \multicolumn{2}{|c|}{ Insured } & \multicolumn{2}{|c|}{ Dropped out } \\
\hline & Frequency & Percentage & Frequency & Percentage \\
\hline No visits & 346 & 84.3 & 257 & 90.8 \\
\hline 1 & 36 & 8.7 & 16 & 5.6 \\
\hline 2 & 17 & 4.1 & 5 & 1.7 \\
\hline More than 2 & 11 & 2.6 & 5 & 1.7 \\
\hline Total individuals & 410 & 100 & 283 & 100 \\
\hline
\end{tabular}

$\mathrm{HMF}=$ Health mutual fund policyholders $(22 \%)$ were unemployed. The policyholders were predominantly $(72 \%)$ employed in the unorganized sector.

Table 4 displays number of out-patient visits by insured and dropped out individuals. The comparative analysis of out-patient care utilization amongst insured and dropped out individuals shows that the out-patient care utilization amongst insured individuals was higher than the out-patient care utilization among dropped out individuals. Nearly $60 \%$ of policyholders preferred private health care provider in the event of hospitalization. $99 \%$ of policyholders preferred out-patient care from private providers. The most common reason cited was the geographical access to the provider, closer to home. Only $7 \%$ of policyholders sought treatment for out-patient care from the health care provider within the network of HMF. Majority of policyholders purchased medicines from a private pharmacy. Only $27 \%$ policyholders bought medicines from the government hospital and private clinic pharmacy.

Table 5 shows the composition of out-patient care by the insured individuals as well as composition of in-patient care expenditure by the insured individuals within 1-year prior to the date of survey. The mean out-patient care expenditure by the insured individuals in 1-month before the date of survey was found to be Rs. 454. After analyzing the share of direct and indirect costs separately, the OOP payment was found to be highest on the medicines. After analyzing the share of direct and indirect costs separately, it was seen that nearly one fifth of the expenditure was incurred due to indirect costs such as transportation, wage loss of the patient, wage loss of a caring person and interest paid on the amount borrowed to meet expense.

Total out-patient care expenditure per annum was calculated by multiplying expenditure incurred in 1-month by 12 and then added into in-patient care expenditure incurred during the past year to obtain total health care related expenditure per annum. The total health care expenditure per annum was found to be in the range of Rs. 450-Rs.108,480. The mean expenditure was found to be Rs. 17,602 with a standard deviation of Rs.18, 876.

\begin{tabular}{|c|c|c|c|c|c|c|c|c|}
\hline \multirow[t]{2}{*}{ Costs } & \multicolumn{4}{|c|}{ Composition of out-patient care expenditure } & \multicolumn{4}{|c|}{ Composition of in-patient care expenditure } \\
\hline & Minimum & Maximum & Mean & $\begin{array}{r}\text { Share of total } \\
\text { expenditure \% }\end{array}$ & Minimum & Maximum & Mean & $\begin{array}{r}\text { Share of total } \\
\text { expenditure \% }\end{array}$ \\
\hline Direct costs $(A)$ & & & & 91 & & & & 82 \\
\hline Consultation charges & 0 & 300 & 150 & 18 & 0 & 1500 & 500 & 4 \\
\hline Charges for surgical procedures & 0 & 3000 & 500 & 13 & 0 & 10000 & 4280 & 39 \\
\hline Medicines & 0 & 2000 & 850 & 38 & 0 & 3000 & 2567 & 19 \\
\hline Investigations & 0 & 4000 & 375 & 22 & 0 & 2000 & 897 & 18 \\
\hline Diet & & & & & 0 & 1000 & 458 & 1 \\
\hline Bed charges & & & & & 0 & 1200 & 672 & 3 \\
\hline Indirect costs $(B)$ & & & & 9 & & & & 18 \\
\hline Transportation & 0 & 100 & 40 & 2 & 0 & 500 & 256 & 1 \\
\hline Wage loss of the patient & 0 & 2000 & 500 & 6 & 0 & 5000 & 2000 & 8 \\
\hline Wage loss of a caring person & 0 & 1000 & 300 & 1 & 0 & 2500 & 1000 & 3 \\
\hline $\begin{array}{l}\text { Interest paid on the amount } \\
\text { borrowed to meet expenses }\end{array}$ & 0 & 0 & 0 & 0 & 0 & 2000 & 900 & 6 \\
\hline Total $(A+B)$ & 0 & 4150 & 454 & 100 & 450 & 90,000 & 12,148 & 100 \\
\hline
\end{tabular}


The sources of financing healthcare varied depending on the amount of expenditure incurred during the illness episode and aggregate income of the household. The main source of financing in case of out-patient care was found to be savings of the household (92\%). In the case of in-patient care, households financed healthcare through multiple sources. One-fourth of the households had taken loan from informal money lender to cope up with health care expenditures.

\section{Extent of financial protection offered through health mutual fund}

The extent of financial protection provided by HMF was determined by calculating the percentage of the amount reimbursed through HMF against the total health care expenditure incurred by the household during past 1-year before conducting the survey. More than one-half of the households (56\%) gained financial protection in the range of $20-40 \%$ of total health care expenditure in 1-year. Mean financial protection gained through the scheme was calculated to be $36 \%$ with a standard deviation of $22.7 \%$.

\section{Drop-out among past members of health mutual fund}

One-third of the past members of the scheme (31\%) dropped out of the scheme as they did not receive or perceived any benefit from the HMF scheme. One-fourth of the interviewed past members discontinued the enrollment into the scheme after repayment of the loan. Other reasons cited by the past members were inability to pay a premium, member of Employees State Insurance Scheme, unsatisfactory services from network provider and past negative experiences including claim rejection or low reimbursement.

\section{DISCUSSION}

The study makes an attempt to understand the mechanism of providing financial protection against risk of illness to the urban poor through the mutual model of CBHI. The socioeconomic profile of the population covered under the HMF scheme shows that the scheme has been able to cover the socially marginalized people belonging to lower castes and minority community. This population is mainly employed in the unorganized sector and belongs to low income group. It is important to note that though this population group is socioeconomically lagging behind, none of the central or state-sponsored health insurance schemes have so far been able to reach out to them. This population was only covered under the HMF. The enrollment into the HMF shows dominance of females as policyholders. This can be attributed to the design and implementation of the loan linked model of the fund. The overall design of the model requires active participation of members through monthly group meetings. Majority of the women are home based workers supplementing the household income while managing homes. Women can participate in these meetings as most of the men are involved in outdoor activities. Hence, the number of female members in micro-credit program and HMF is more than the male members. This factor gives an additional dimension of women empowerment to HMF.
The higher utilization of out-patient care amongst insured individuals compared to drop out individuals may be attributed to the human behavior to consume more health services when insured. Thus, musicalizing some of the nonhealth problem into a health problem and seeking medical services at one end and at the other, increasing the cost of health care by consuming unwanted resources. In addition, the sample of insured households was chosen purposively with at least one hospitalization event 1-year prior to the date of survey. Hence, the higher utilization of out-patient care among insured individuals cannot be attributed due to HMF alone. The HMF scheme has included discounts on out-patient care through the health care providers within the network to reduce OOP expenditure. The findings of this study reveal that members preferred health care providers other than the network providers. Members chose the providers who were closest to their residence. Availability of the provider and the effectiveness of treatment were considered more important rather than the affordability at time of seeking treatment. Thus, the objective of reducing OOP remains an existing issue in the case of out-patient care. In the case of hospitalization members preferred private hospitals over government hospitals even though, health care services offered by government hospitals were cheaper. Some of the reasons for preferring private hospitals were less waiting period, proximity from residence. Members reported that they received better and prompt treatment from private providers. Medicines have made a significant contribution to OOP expenditure. All members had to buy medicines from the private pharmacy in addition to medicines bought from the government or private clinic pharmacy. HMF has made tie-ups with some of the private pharmacies to provide discount on medicines to members. However, the majority of members were not aware of this benefit.

Health mutual fund is playing important role in providing financial protection against high frequency illnesses, which are generally not covered under state-sponsored scheme. HMF appears to provide a significant amount of financial protection in case of single hospitalization event. However, the mean amount reimbursed through HMF was found to be $36 \%$ of total healthcare expenditure incurred per annum for insured households. This finding signifies that the financial protection provided through HMF is still on the lower side when compared with annual OOP expenditure due to health by the household. In addition to direct costs of healthcare services, indirect costs such as transport to healthcare facility, wage loss of the patient and the caring person during the illness episode and interest on the loan taken to meet expenses cause an extra financial burden on the households. Thus, the coverage for a hospitalization event provides partial financial coverage to the insured household.

Multiple issues emerged while examining the reasons behind the members dropping out of the scheme and hence challenging renewal rate of the scheme and sustainability. Among the multiple reasons, poor perceived benefits from the scheme, previous negative experience of rejection of claims in the past, inability to pay premium 
and preferences of the members to seek health care (out-patient) from providers who was are not the part of the network were among the cited reasons.

\section{CONCLUSION}

In the light of the evidences on the effectiveness of the innovative financing mechanism through HMF, it can be argued that the HMF is a promising solution to provide financial protection against risk of illnesses to the marginalized population in the urban region. The model provides some degree of risk protection which was not available to this segment population previously. In the pluralistic environment of Indian health care system, there is a need of multipronged strategies to reduce the burden of OOP expenditure due to health. Single handedly archiving the objective of reducing the OOP alone by HMF seems to be an over ambitious goal. CBHI models like HMF can only supplement the efforts made by government sponsored health insurance schemes to reduce OOP in order to prevent impoverishment of marginalized population due to health related expenditures.

\section{REFERENCES}

1. National health accounts India 2004-05. National Health Accounts Cell, Ministry of Health and Family welfare, Government of India, New Delhi; 2009. p. 3

2. Peters D, Yazbeck A, Sharma R, Ramana G, Pritchett L, Wagstaff A. Better Health Systems for India's Poor. Washington: World Bank; 2002. p. 347.

3. Ghosh S. Catastrophic payments and impoverishment due to out-of-pocket health spending. Econ Polit Wkly 2011;xlvi:63-70.

4. Srinath RK, Selvaraj S, Rao KD, Chokshi M, Kumar P. A critical assessment of the existing health insurance models in India. A Report Submitted to the Planning Commission of India, January, New Delhi; 2011.
5. Devadasan N, Ranson K, Van Damme W, Criel B. Community health insurance in India, an overview. Econ Polit Wkly 2004;39:3179-83.

6. Dror D, Jacquier C. Micro insurance: Extending health Insurance to the excluded. Int Soc Secur Rev 1999;52:71.

7. Michielsen J, Criel B, Devadasan N, Soors W, Wouters E, Meulemans H. International journal for quality in health care, 2011;23:471-86.

8. Devadasan N, Nandraj S. Health insurance in India. Planning and Implementing Health Insurance Programmes in India: An Operational Guide. Institute of Public Health; Bangalore, India 2006. p. 13.

9. Eleventh Five Year Plan (2007-2012), Planning Commission. New Delhi: Government of India/Oxford University Press; 2008.

10. National Rural Health Mission (2005-2012), Ministry of Health and Family Welfare. New Delhi: Government of India; 2005.

11. Jakab M, Krishnan C. Community Involvement in Health Care Financing: Impact, Strengths and Weakness. A Survey of the Literature. Draft Preparation for the WHO Commission for Macro-Economics and Health. Washington, DC: The World Bank; 2001.

12. Atim C. The Contribution of Mutual Health Organizations to Financing, Delivery and Access to Health Care: Synthesis of Research in Nine West and Central African Countries. Technical Report No.18. Partnership for Health Reform. Bethesda, Maryland: Abt. Associates Inc.; 1998. p. 82.

13. Leist H, Radermacher R. Brief Technical Report on Swasthyapurna Mutual Health Fund. Bonn: Deutsche Gesellschaftfur Technische Zusammenheit; 2004.

14. Dror DM, Radermacher R, Khadilkar SB, Schout P, Hay FX, Singh A, et al. Microinsurance: innovations in low-cost health insurance. Health Aff (Millwood) 2009;28:1788-98.

15. Bauchet J, Dalal A, Mayasudhakar P, Morduch J, Radermacher R. Can Insurers Improve Healthcare Quality? Evidence from a Community Micro-insurance Scheme in India. New York: The Financial Access Initiative; 2010.

16. McGuinness E. A Fine Balance: A Case Study of the Client Value of Health Microinsurance-Uplift I.A. Microfinance Opportunities; 2011.

How to cite this article: Salvi R, Chakravarty N. Health mutual fund: Reality or a myth?. Int J Med Public Health 2014;4:451-7.

Source of Support: Nil, Conflict of Interest: None declared. 